\title{
New Options for the Management of GERD
}

\author{
Jennifer L. Wilson • Brian E. Louie
}

Published online: 29 April 2014

(C) Springer Science + Business Media New York 2014

\begin{abstract}
Novel GERD treatment modalities have emerged over the past decade as alternatives to proton pump inhibitors or traditional laparoscopic Nissen fundoplication. Four new devices-LINX, TIF, EndoStim and Stretta-have attempted to improve upon the limitations of these traditional therapies. While each is promising, only the LINX device addresses the patient's symptoms, achieves objective control of acid and has limited the need for additional therapies. Further comparative research and longer term follow-up are necessary to determine the role of these therapies in the algorithm of GERD management.
\end{abstract}

Keywords Gastroesophageal reflux disease - GERD . Management · LINX · EndoStim · TIF · EsophyX - Stretta · Reflux $\cdot$ Nissen $\cdot$ Fundoplication $\cdot$ Esophagitis $\cdot$ Hiatal hernia

\section{Introduction}

Gastroesophageal reflux (GERD) affects up to $27.8 \%$ of adults in North America, and the incidence has been increasing worldwide [1]. The primary options for treatment have been proton pump inhibitors (PPI) or laparoscopic Nissen fundoplication (LNF). The vast majority of patients

This article is part of the Topical Collection on Esophageal/Reflux Surgery.

J. L. Wilson · B. E. Louie $(\bowtie)$

Division of Thoracic Surgery, Swedish Cancer Institute, 1101

Madison Street, Suite 900, Seattle, WA 98104, USA

e-mail: brian.louie@swedish.org

J. L. Wilson

e-mail: jen13wilson@gmail.com are managed with PPIs with good control of their symptoms. However, what was once a panacea for treating GERD has been eroded by recent data, suggesting that PPIs are not as effective as believed, with only $32 \%$ of patients achieving complete symptom relief [2], and other reports highlighting long-term side effects such as pneumonia, Clostridium difficile infection, fracture, impaired magnesium absorption, thrombocytopenia, iron deficiency, vitamin B12 deficiency, rhabdomyolysis and acute interstitial nephritis [3].

Despite these outcomes and concerns, a relatively small number of patients will choose the alternative and undergo fundoplication, which has been demonstrated to be as effective if not more effective than PPIs in a randomized control trial [4]. The patient's reticence may be due to the perceived invasiveness of a laparoscopic operation, the potential side effects such as symptomatic gas bloat $(40 \%)$, hyperflatulence $(57 \%)$ and dysphagia $(11 \%)$ or even the durability of LNF, which is estimated at $85 \%$ at 5 years [5•]. This has resulted in a significant treatment gap with a large number of patients who are unsatisfied with PPIs yet are unwilling to undergo LNF. Alternative treatment modalities have been developed to attempt to close this treatment gap. In this report, we review the recently developed surgical and endoscopic options for managing GERD that hope to address this therapy gap.

\section{Methods}

Devices or systems included in this review were selected if they have received approval from the Food and Drug Administration (FDA) for use in the USA or have CE Mark approval in Europe. In addition, the device was required to have published results in a medical journal. The devices meeting these criteria were: 
- LINX reflux management system (Torax Medical, Shoreview, MN, USA).

- EsophyX $\mathrm{X}_{2}$ transoral incisionless fundoplication (TIF) (Endogastric Solutions, Redmond, WA, USA).

- Stretta (Mederi Therapeutics, Greenwich, CT, USA);

- EndoStim (Endostim BM, The Netherlands).

The success of most GERD treatments is often determined by the symptomatic improvement reported by the patient. However, this is not the only measure of success. In this review, each device or procedure was assessed by several factors including:

(1) Symptom improvement (e.g., effect on presenting symptoms, durability, development of new symptoms and patient perception of overall success);

(2) Effects on esophageal function and mucosal integrity (e.g., esophageal acid exposure, mucosal integrity);

(3) Need for additional therapy (medication use and reoperations) $\left[6^{\bullet}\right]$.

\section{Results of Current Options for GERD Treatment}

Both PPIs and antireflux surgery have been shown to be effective in the management of chronic GERD in two randomized trials at 5 [5•] and 12 years [7]. The LOTUS trial demonstrated similar rates of remission of GERD at 5 years (92\%-PPIs vs. $85 \%$-LNF, $p=0.48$ ), but these rates dropped to 46 and $37 \%$, respectively, when patients reach 12 years of follow-up [7]. Subjectively, in these trials, the classic symptoms of heartburn and regurgitation were better controlled with surgery, but this comes in exchange for higher rates of dysphagia, flatulence and an inability to belch/vomit. Despite these differences, the quality of life of both treatment arms remained excellent and very similar across the groups. Only the LOTUS trial reported objective $\mathrm{pH}$ data [5•]. Patients treated with PPIs had $\%$ time $\mathrm{pH}<4$ increase from 12.1 to $62.1 \%$, whereas patients who underwent LNF remained stable from $12.4 \%$ at baseline to $11.4 \%$ at 5 years [5•].

\section{New Options for GERD Treatment}

\section{LINX: Reflux Management System}

The LINX Reflux Management System (LINX) consists of a ring of titanium-coated magnets that are designed to augment the lower esophageal sphincter (see Fig. 1). The mechanism of action of this device is based on the concept of a 'loose ligature' around the LES as first described in
1983 by Samelson et al. [8]. This loose ligature was shown to prevent LES shortening and thus opening of the LES to increasing gastric distension (see Fig. 1).

Current indications for implantation of the LINX device include patients with objective evidence of GERD, hiatal hernia $<3 \mathrm{~cm}$ in axial length, normal esophagogastric motility, and the absence of Barrett's esophagus. The full manufacturer recommended and FDA approved patient selection criteria are listed in Table 1.

The LINX device is implanted laparoscopically using four or five ports in a similar configuration to LNF. The location of device placement is identified on the patient's right side at the level of the hepatic branch of the anterior vagus nerve. Next, the space between the lateral left crus and the posterior fundus is dissected. After opening the gastrohepatic ligament around the hepatic branch of the vagus nerve, a tunnel is created behind the esophagus directed toward the area dissected on the left crus. A 1/4inch penrose drain is placed through the tunnel behind the esophagus. The posterior vagus nerve is then identified and isolated by placing the penrose inside of the nerve and around the GEJ.

On the anterior surface, the peritoneum and fat are cleared with monopolar cautery taking care to preserve the anterior vagal nerve and thus creating a "trench" for the device to sit in on the surface of the esophagus. The sizing device is placed in the tunnel between the posterior vagus and the esophagus to guide size selection. After sizing, the appropriately sized device is situated in the tunnel and around the esophagus and secured with the clasp or sutures depending on which version of the device is implanted. Hiatal hernias up to $3 \mathrm{~cm}$ in size can usually be closed with a single crural suture in most cases.

Patients are allowed to drink liquids immediately after the procedure and start on a regular diet within $24 \mathrm{~h}$ of the procedure. PPIs are stopped the morning of the procedure. For most patients, only oral analgesics are necessary for up to 2-4 days.

\section{Outcomes and Results of LINX}

The current outcome data on LINX are derived from two major publications that evaluated 100 patients from the USA [9•] and 100 patients from Italy [10]. Patients in both trials were among the first to undergo device implantation, and the majority were part of a clinical trial.

In both studies, the patient's GERD symptoms as measured by the GERD HRQL showed significant ( $\geq 50 \%$ ) improvement from baseline in $92 \%$ [9•] and a normalization of the median GERD-HRQL from 16 to 2 on PPIs before placement [10]. The symptom of regurgitation was significantly improved from nearly 60-1 \% 3 years after device implantation [9•]. Bloating was reported in only 
Fig. 1 LINX system: a antireflux action; $\mathbf{b}$ relaxation with food bolus. Photos courtesy of Torax Medical Inc.

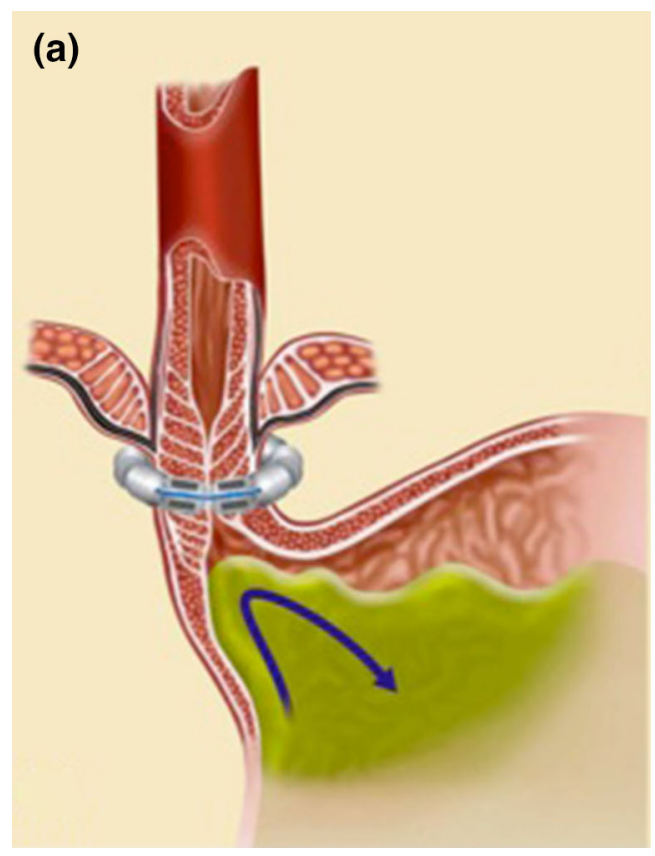

Table 1 LINX inclusion and exclusion criteria

Inclusion criteria
18-85 years old
Typical reflux symptoms at least partially responsive to PPI
therapy
Abnormal esophageal acid exposure
Normal contraction amplitude and wave form in the esophageal
body
Exclusion criteria
Symptoms of dysphagia
Previous upper abdominal surgery
Previous endoluminal antireflux procedures
Sliding hiatal hernia $\geq 3$ cm
Grade B, C or D esophagitis (LA classification)
Barrett's esophagus
BMI $>35$ kg/m ${ }^{2}$
Titanium, stainless steel, nickel or ferrous allergy
Gross esophageal anatomic abnormalities

Data from Bonavina et al. [10, 30]

$P P I$ proton pump inhibitor, $B M I$ body mass index

$2 \%(2 / 100)$ of patients, while $99 \%(99 / 100)$ of patients reported ability to belch and vomit at follow-up [10]. Lastly, patient satisfaction was reported in $87 \%$ (83/95) of patients at last follow-up [10].

Consistent with symptomatic improvements, the objective measures of reflux also improved after LINX placement. The mean DeMeester score decreased from 36.6 to $13.5(p<0.001)$, and $\%$ time $\mathrm{pH}<4$ decreased from 10.9 to $3.3(p<0.001)\left[9^{\bullet}\right]$. These results appear to be durable with post-implantation $\mathrm{pH}$ studies at a mean of 4.2 years in 20 patients showing $\%$ time $\mathrm{pH}<4$ was lowered from 8 to $3.2 \%$, and the DeMeester score was reduced from 30.1 to 11.2 [10]. Normalization of $\mathrm{pH}(\%$ time $\mathrm{pH}<4$ for $\leq 4.5 \%$ of the time) was $67 \%(20 / 30)$ at last follow-up and $75 \%(15 / 20)$ at 5 years [10]. Likewise, normalization of esophageal acid exposure or a $\geq 50 \%$ reduction was achieved in $80 \%$ (25 of 30) patients [10]. Additionally, over $85 \%$ of patients were off PPIs at 3 years in both studies $[9 \bullet, 10]$.

It is recommended that patients with a LINX should have it removed before undergoing MRI. However, few data have been reported on this issue. Bonavina et al. [10] reported their results of $8 / 100$ patients who underwent MRI scanning after LINX implantation, and two of these patients reported discomfort during the scan. One had odynophagia and dysphagia for 3 months, and one patient reported occasional heartburn after the MRI [10]. Due to this report, MRI should be avoided if possible in patients who have had a LINX implant.

Transoral Incisionless Fundoplication (TIF) with the Esophy $\mathrm{X}_{2}$ Device

The EsophyX $\mathrm{X}_{2}$ antireflux device (see Fig. 2) used in conjunction with a flexible endoscope enables the creation of a partial anterior (up to $270-300^{\circ}$ ) esophagogastric fullthickness fundoplication by using proprietary tissuemanipulating elements and 12 or more polypropylene fasteners [11-13]. This system was designed to mimic a LNF by using an endoscopic technique. 
Fig. 2 a TIF EsophyX device.

b Endoscopic view post

fundoplication. (C)[2013]

EndoGastric Solutions, Inc. A,

$E$ Endoscopic view post Nissen fundoplication. $B-D$,

$F$ Endoscopic view post TIF.

Photos courtesy of EndoGastric

Solutions Inc.

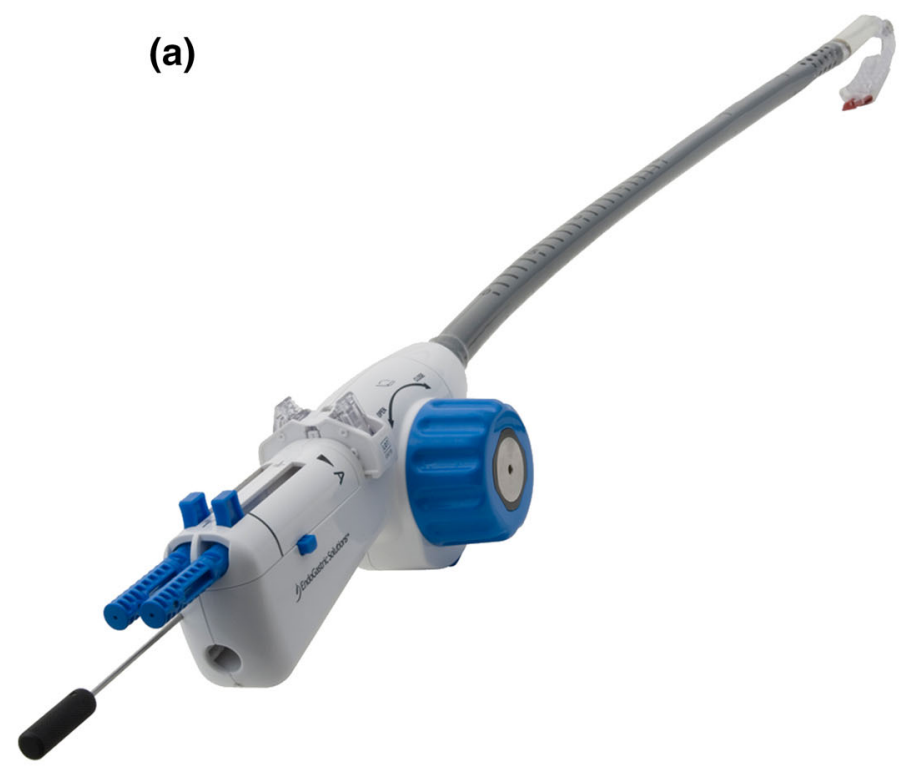

(b)

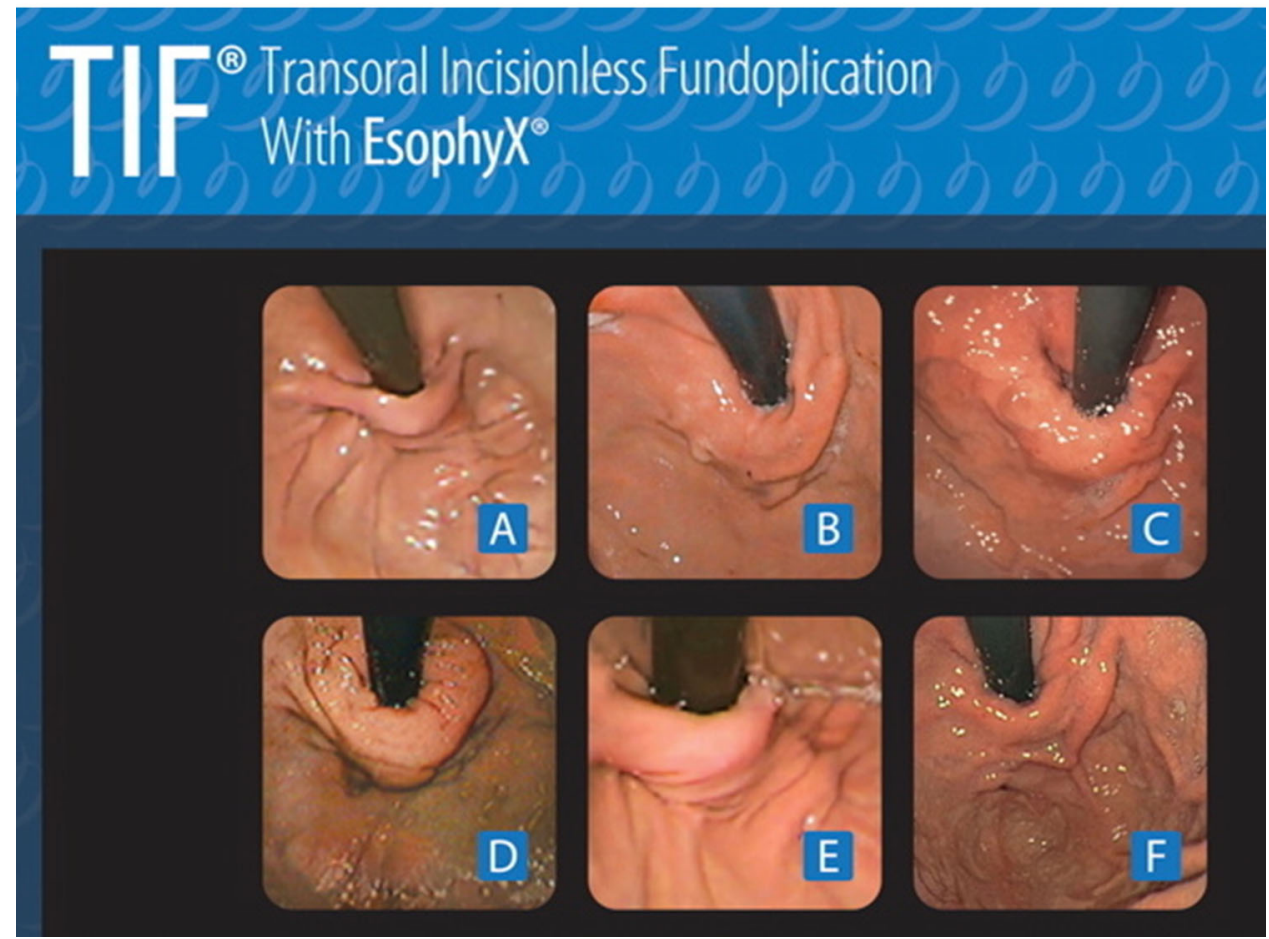

Current indications for transoral incisionless fundoplication include patients with objective evidence of GERD and hiatal hernia $<3 \mathrm{~cm}$ in axial length. Inclusion and exclusion criteria are listed in Table 2 [14•].

The procedure is performed endoscopically under general anesthesia with the patient in the left lateral decubitus position. The Esophy $\mathrm{X}_{2}$ device has a handle where controls are located and a chassis (18 $\mathrm{mm}$ diameter) through which the endoscope is inserted and control channels run (see Fig. 2). The endoscopic plicating and suturing mechanism works in a complex but coordinated way as described by Bell et al. [15]. Plication is facilitated by a vacuum-powered tissue invaginator, a tissue mold, which retroflexes to push tissue against the device for plication and a helical screw that allows caudal manipulation of tissue between the mold and shaft. Additionally, there are also two stylets that fire through the esophagus and fundus to guide $\mathrm{H}$-shaped fastener deployment.

During the procedure, one physician controls fastener implantation and one physician operates the endoscope. 
Table 2 EsophyX transoral incisionless fundoplication (TIF) inclusion and exclusion criteria

\section{Inclusion criteria \\ Age 18-75 years \\ GERD for $>1$ year \\ Daily PPI use for $>6$ months \\ Moderate to severe typical or atypical GERD symptoms off PPIs \\ Complete (responders) or partial (nonresponders) symptom control on PPIs \\ Deteriorated gastroesophageal junction (Hill grade II or III) \\ Proven gastroesophageal reflux by either endoscopy, ambulatory $\mathrm{pH}$, or barium swallow testing \\ Willingness to undergo $\mathrm{pH} / \mathrm{impedance}$ testing, if required \\ Willingness to adhere to postoperative diet for 6 week \\ Availability for follow-up visits at 6 and 12 months \\ Willingly and cognitively signed informed consent \\ Exclusion criteria \\ $\mathrm{BMI}>35 \mathrm{~kg} / \mathrm{m}^{2}$ \\ Incompletely reducible hernia with residual $>5 \mathrm{~mm}$ \\ Portal hypertension and/or varices \\ Esophagitis grade D; Barrett's esophagus $>2 \mathrm{~cm}$; esophageal ulcer; fixed esophageal stricture or narrowing \\ Active gastroduodenal ulcer disease \\ Gastric outlet obstruction or stenosis \\ Gastroparesis or delayed gastric emptying confirmed by solid- phase gastric emptying study, if patient complains of postprandial satiety during assessment \\ Coagulation disorder \\ History of any of the following: resective gastric or esophageal surgery, antireflux surgery with anatomy unsuitable for TIF procedure per physician judgment, cervical spine fusion Zenker's diverticulum, esophageal epiphrenic diverticulum, achalasia, scleroderma, dermatomyositis, eosinophilic esophagitis or cirrhosis \\ Pregnancy or plans of pregnancy in the next 12 months \\ Enrollment in another device or drug study that may confound the results}

Data from Bell et al. [14•]

$G E R D$ gastroesophageal reflux disease, $P P I$ proton pump inhibitor, $B M I$ body mass index

First, an initial helical screw is deployed at 12 o'clock at the Z-line; next, three anterior rotation plication sets are created with the tissue mold, tissue invaginator, stylets and fasteners from 2 to 4 o'clock. The device is then rotated, and three posterior plication sets are deployed in a similar fashion from 7 o'clock toward 10 o'clock. The tissue mold is again rotated, and two anterior longitudinal plication sets are created at 12:30-2 o'clock. Next, the device is repositioned, and the final greater curve plication is created at 5 o'clock. Final endoscopy is performed to assess plication for bleeding or perforation.

Cadiere et al. [13] reported that the procedure took a median of $77 \mathrm{~min}$, and either two gastroenterologists or one surgeon and one gastroenterologist performed each procedure. Patients are typically discharged on post procedure day 1 and treated with PPIs for 2 weeks. A liquid diet without carbonation for 2 weeks followed by a soft diet for 2 weeks is recommended [13]. A water-soluble contrast study prior to discharge is recommended by some authors [15].

\section{Outcomes and Results of TIF}

The current results of the TIF procedure are based on $\sim 25$ publications. There was one multicenter review of 86 patients published in 2008 [13], and the remaining studies have been single-center reviews.

Subjective data for the TIF procedures showed significant improvements in the GERD-HRQL. At 6 months, scores were reduced by more than 50 in $80 \%$ of patients, but only normalized in $50 \%$ of patients [16], whereas at 12 months, reduced GERD-HRQL ( $\geq 50 \%)$ scores were reported in $73 \%(58 / 79)$ of patients [13]. Complete symptom elimination (GERD-HRQL score $\leq 12$ ) occurred in $75 \%$ of patients, and $65 \%$ of patients were satisfied with their condition [13]. However, in this same study, only $56 \%$ of patients were 'cured' of GERD (i.e., alleviated symptoms and off PPIs), while $22 \%$ had improved symptoms and $22 \%$ had ongoing GERD [13].

In a large study published in 2012 examining the TIF technique in 100 patients, $80 \%$ discontinued acid suppression medications after surgery [14•]. Comparatively, in a different study, only 8/19 (42\%) of patients were completely off PPIs, while $32 \%(6 / 19)$ were taking occasional PPIs and $26 \%$ (5/19) were taking daily PPIs at 36 months [17]. Most patients that had dysphagia before the procedure had improved swallowing after TIF (24/27, $89 \%)$, and no patients developed new dysphagia [14•]. Additionally, TIF did not affect the number of gas reflux episodes, allowing venting of gastric air as needed in a small series of 15 patients [18].

Objective measures of reflux control in 24 of 36 patients who underwent pre- and post-procedure $\mathrm{pH}$ testing off PPIs showed the mean $\%$ time $\mathrm{pH}<4$ was reduced from 10.4 to $1.7(p=0.003)$ and had normalized post TIF in $61 \%$ of patients [16]. However, four patients actually had an increased $(>5 \%)$ time $\mathrm{pH}<4$ after TIF [16]. The average number of reflux episodes per $24 \mathrm{~h}$ was reduced from 20.8 to $8.4(p<0.001)$ after TIF and normalized in $89 \%$ of patients [16]. DeMeester scores were also significantly reduced from 37.1 to 16.9 and normalized in $56 \%$ of patients [16].

Complications occurring during TIF have been notable for esophageal perforation and post-procedure bleeds. In a series of 87 patients, there were two esophageal perforations during device insertion requiring operative 

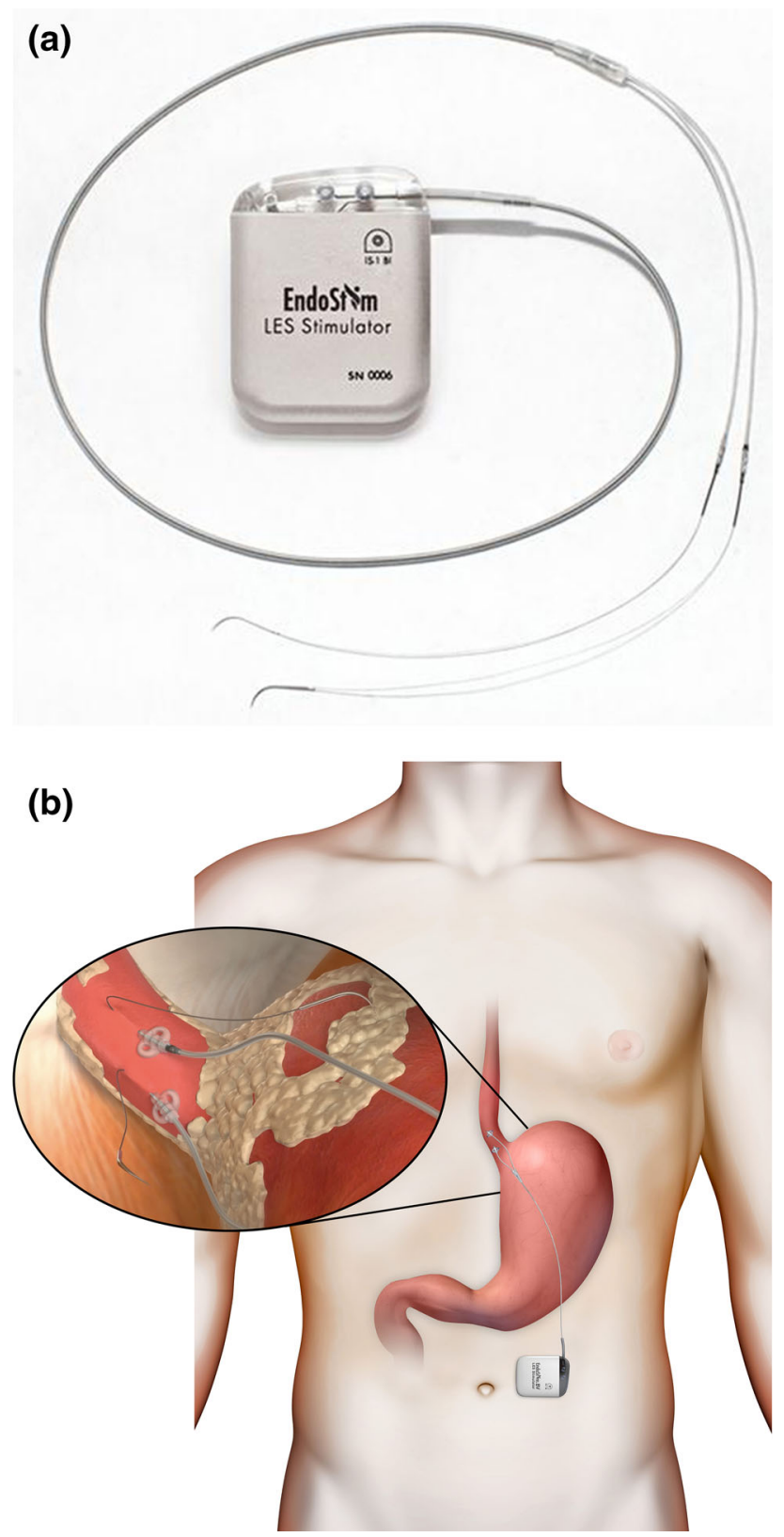

Fig. 3 a EndoStim device. b Implanted view. Photos courtesy of EndoStim Inc.

intervention with patients being discharged on day 6 and 21 [13]. There was also one patient who required blood transfusion of 4 units PRBC related to hemorrhage post TIF [13]. Bleeding was controlled endoscopically with clips and fibrin glue injection.

Two studies tracked patients who required additional procedures for refractory symptoms of GERD. First, a total of $5(13.5 \%)$ patients underwent additional procedures within 3-6 months including two patients who had a repeat TIF procedure and 3 that subsequently underwent LNF [16]. However, in a series of 38 patients at 36 months
Table 3 EndoStim inclusion and exclusion criteria

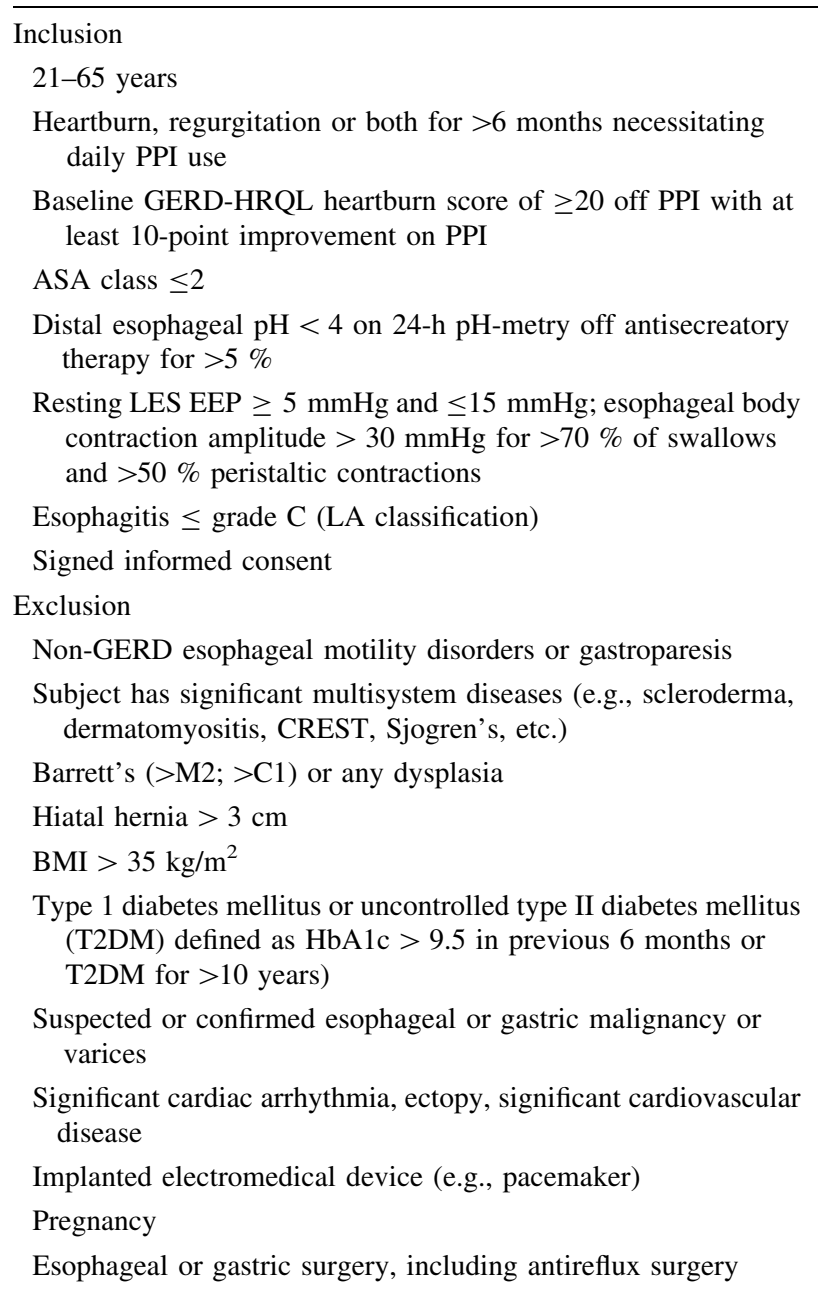

Data from Rodriguez et al. [21]

$P P I$ proton pump inhibitor, GERD-HRQL gastroesophageal reflux disease-health related quality of life, LES lower esophageal sphincter, $B M I$ body mass index

follow-up, $37 \%(14 / 38)$ of patients requested revisional LNF because of persistent GERD symptoms [17]. Further analysis of patients undergoing conversion from TIF to LNF have shown no increased operative morbidity [19]. The $\mathrm{H}$ fasteners were partially dislodged in all of these cases. However, another review of 11 patients after TIF that went on to require LNF did report increased operative morbidity [20]. In this series, previous TIF was associated with a risk of gastric injury during $\operatorname{LNF}(2 / 11,18.2 \%)$ and an increased rate of post-fundoplication dysphagia (3/11, $27.2 \%)$ [20].

\section{EndoStim}

The EndoStim device is an implantable electrical stimulator that delivers long-term electrical stimulation therapy 
to the lower esophageal sphincter (see Fig. 3). It consists of two bipolar stitch electrodes, an implantable pulse generator (IPG) and an external programming device. The programmable stimulator delivers electrical impulses into the LES at set intervals. The impulses have been shown to increase LES pressure in animals and humans, which is thought to result in GERD control [21].

The EndoStim device is not currently approved for sale in the US. However, it received the CE (Conformité Européenne) mark in 2012 for use in Europe. Patients eligible for this device have symptomatic reflux, are PPI dependent with no significant hiatal hernia and have a BMI $<35 \mathrm{~m} / \mathrm{kg}^{2}$. Inclusion and exclusion criteria are outlined in Table 3 [21].

The EndoStim device is placed laparoscopically as described by Rodriquez et al. [22]. The GEJ is dissected with care to preserve the phrenoesophageal ligament and vagus nerve branches. The goal is obtaining $2-3 \mathrm{~cm}$ of intra-abdominal esophageal length, which may require transhiatal mobilization of the distal esophagus. If this is the case, the posterior crura are closed after device implantation. Next, upper endoscopy is performed, and the $\mathrm{Z}$ line is identified via trans-illumination. Electrodes are placed laparoscopically while simultaneously performing an endoscopy to avoid esophageal perforation. The electrodes are placed away from the vagal nerves into the muscularis propria of the LES $10 \mathrm{~mm}$ away from one another. The electrode wires are then tunneled to a subcutaneous pocket and attached to the device. The device is tested intraoperatively and turned on $12 \mathrm{~h}$ after the procedure. Electrical stimulation parameters reported in prior studies were $20 \mathrm{~Hz}, 215 \mathrm{~ms}$ and 3-8 mA in 30-min sessions [22]. Patients are typically discharged home on postoperative day 1 ; it is unclear from these series whether they were on PPIs or diet restricted.

\section{Outcomes and Results of EndoStim}

Clinical results of EndoStim are based on a single openlabeled study of 25 patients reported in three different papers reflecting the duration of follow-up [21, 22, 23•].

Subjectively, the GERD HRQL was reduced from 9.0 on PPIs and 23.5 off PPI to $2.0(p<0.001)$ at 12 months in a study of 24 patients [22]. In this series, only $4 \%$ of patients were unsatisfied with their current condition at 6-month follow-up [22]. Reflux impacting sleep decreased from 21/24 (88\%) off PPIs to $4 \%(1 / 24 ; p<0.001)$. Dysphagia or odynophagia also decreased from $58 \%$ (14/ 24) off PPIs to $4 \%(1 / 24 ; p=0.001)$ [22].

Objectively, $96 \%(23 / 24)$ of patients were off PPIs at 12 months [23•]. The DeMeester score was reduced from 36.7 to $11.7(p<0.001)[23 \bullet$. Similarly, the $\%$ time $\mathrm{pH}<4$ was reduced in the upright position [10.4 to $4.5 \%$ $(p=0.001)]$ and in the supine position $[6-0.4 \%$ $(p=0.02)$ ] [23•]. At 12 months, $96 \%$ of patients were off PPIs, and $69 \%$ of patients had either normalization or a $>50 \%$ improvement in distal esophageal $\mathrm{pH}[23 \bullet]$.

None $(0 / 24)$ of the patients reported bloating, inability to belch or new dysphagia [22]. In this series, one patient required hospitalization for chest pain and ultimately was diagnosed with esophageal spasms and discharged on antispasmodics without further symptoms. Three patients had implant site pain, one had a localized infection and one reported dyspepsia; three had transient nausea [22].

\section{Stretta}

The Stretta device delivers low-power radiofrequency energy to the LES and GEJ via endoscopic balloonmounted needles, thereby altering the neuromusclar function of the LES (see Fig. 4). It is reported that the therapy remodels the LES and gastric cardia musculature, thereby improving reflux control by decreasing both the number of lower esophageal sphincter relaxation episodes (tLESR) [24] and GEJ compliance, which is thought to be due to a neuro-ablative mechanism rather than tissue fibrosis [25].

Study inclusion criteria for Stretta include PPI responsive symptoms, abnormal 24-h $\mathrm{pH}$ study and normal esophageal motility. Exclusion criteria have included Barrett's esophagus and hiatal hernia $>2 \mathrm{~cm}$. Full inclusion and exclusion criteria are outlined in Table 4.

Radiofrequency ablative therapy is performed endoscopically under conscious sedation as described by Dughera et al. [26]. First, endoscopy is performed to measure the distance from the Z-line to the incisors, and then the endoscope is removed. The Stretta catheter is passed transorally and positioned up to $2 \mathrm{~cm}$ proximal to the squamocolumnar junction ( $\mathrm{Z}$ line). The balloon is inflated, and four nickletitanium electrodes are deployed into the esophageal wall. Temperature controlled $\left(65-85^{\circ} \mathrm{C}\right) \mathrm{RF}$ energy $(5 \mathrm{~W})$ is delivered for a set time $(1 \mathrm{~min})$ while the device is irrigated with cooling solution. The needles are withdrawn, and the balloon is deflated prior to repositioning the device. The device is rotated $45^{\circ}$ at a time, and treatment sets are repeated every $0.5 \mathrm{~cm}$, covering an area $2 \mathrm{~cm}$ proximal and $1.5 \mathrm{~cm}$ distal to the $\mathrm{Z}$ line [26]. Six more sets of needle deployments are completed below the cardia for a total of 22 sets. All patients undergo endoscopy immediately after treatment to assess the mucosa. Dughara et al. [26] reported a mean procedure time of $50 \mathrm{~min}$ (range $45-70 \mathrm{~min}$ ). The procedure is performed in the outpatient setting.

\section{Outcomes and Results of Stretta}

In 2012, Perry et al. published a meta-analysis containing 1,441 patients from 18 studies published until 2010 and demonstrated significant improvement in reflux symptoms 


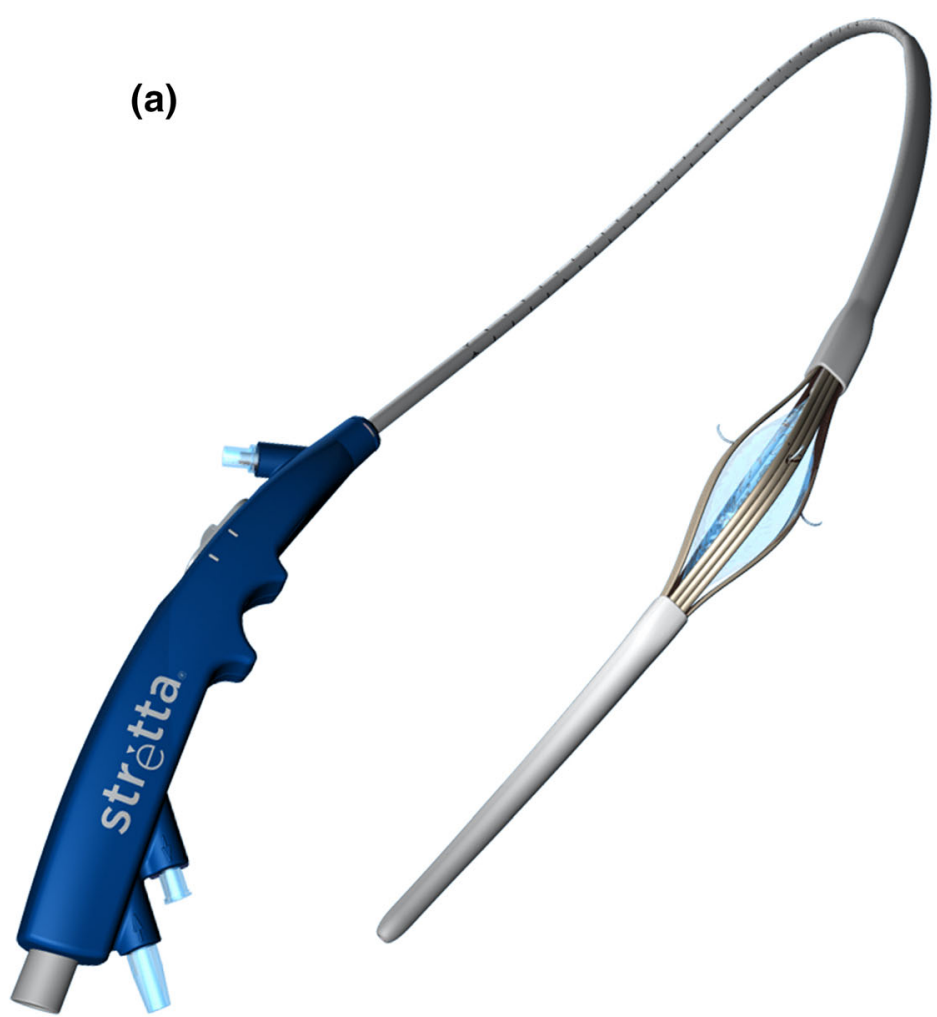

(b)
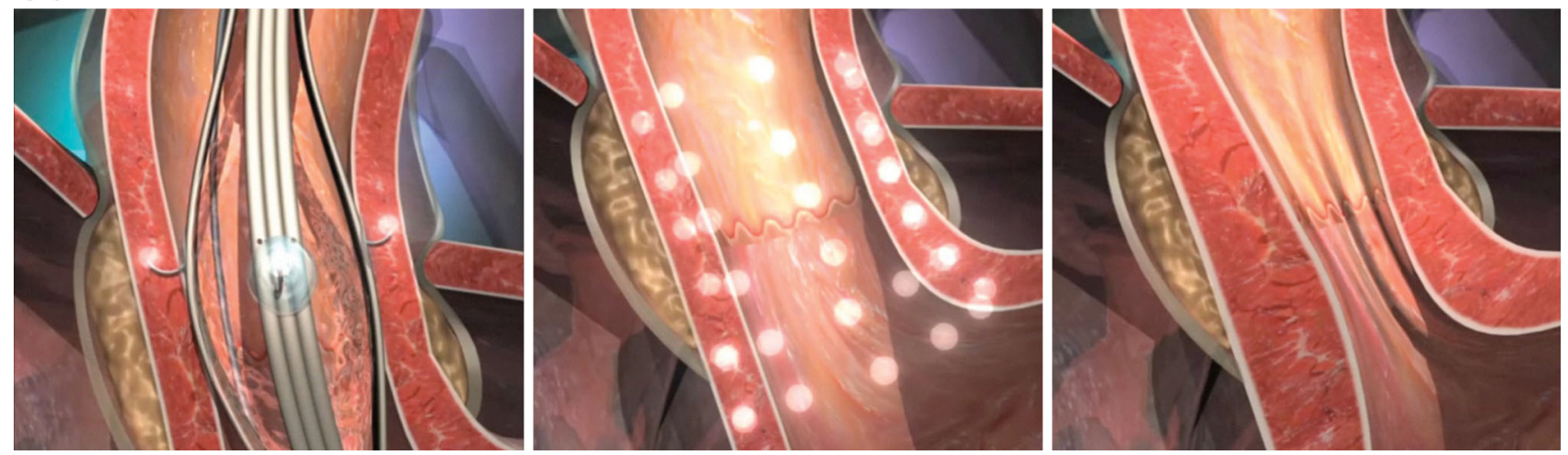

Fig. 4 a Stretta device; b how Stretta works. Photos courtesy of Mederi Therapeutics Inc. (c) 2013 Mederi Therapeutics Inc.

overall [27•]. They reported statistically significant improvements in subjective data of Stretta at mean followup intervals of 9.5-25.2 months. Significant improvements were reported for the GERD-HRQL (26.11-9.25, $p=0.001)$, QOLRAD (3.30-9.25, $p=0.0010)$, SF-36 physical (36.45-46.12, $p=0.001)$ and mental (46.7-55.1, $p=0.0015)$, heartburn score $(3.55-1.19, p=0.001)$ and satisfaction score $(1.43-4.07, p=0.006)$ [27•].

Objectively, the 6- and 12-month follow-up results of a US multicenter prospective open-label trial showed that PPI use in 94 patients decreased from 88 to $30 \%$ at 12 months $(p=0.0001)$, and esophageal acid (\% time $\mathrm{pH}<4)$ exposure decreased from 10.2 to $6.4 \%$ [28].
Similar results were also seen in the meta-analysis with $\%$ time $\mathrm{pH}<4 \quad(10.3-6.5, p=0.003)$, DeMeester score (44.3-28.5, $\quad p=0.0074)$ and LESP (16.5-20.2, $p=0.0302$ ) after Stretta therapy [27•]. In longer term follow-up, additional procedures for reflux occurred in $11.9 \%(13 / 109)$ of patients (6 Nissen, 7 Stretta) [27•].

Stretta was shown to be safe in several series with only minor complications reported [28, 29]. These self-limited complications occurred in $10(8.6 \%)$ of patients and included fever in two patients, superficial mucosal injury due to catheter movement in three patients $(2.5 \%)$ and chest pain requiring narcotic use in two $(1.7 \%)$. Hospitalization was required in one of these patients, sedation 
Table 4 Stretta RFA inclusion and exclusion criteria

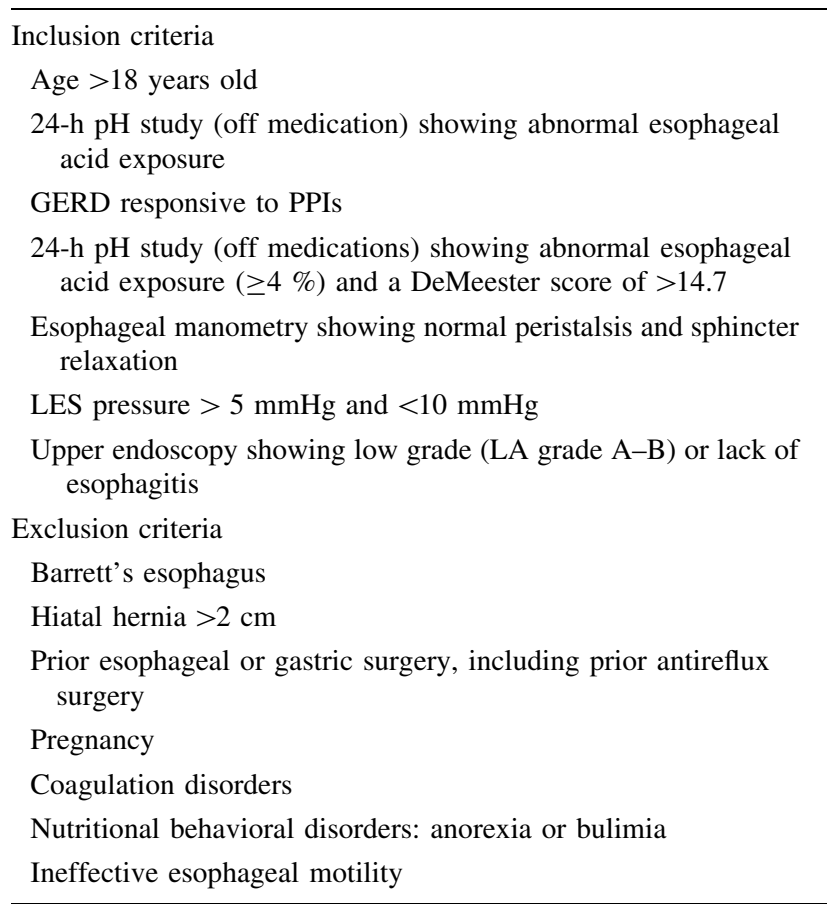

Data from Dughera et al. [26]

$P P I$ proton pump inhibitor, LES lower esophageal sphincter

related self-limiting hypotension in one $(0.8 \%)$ and submental swelling in one $(0.8 \%)$. Similar results were shown in another trials with minor complications including dyspepsia 11/109 (10.1\%), chest discomfort 27/109 (25\%) and minor gastric bleeding 2/109 (1.8\%) [29]. There were no perforations, strictures, new onset dysphagia, bleeding or death reported [26, 28].

\section{Future Roles and Trends}

The ideal therapy for GERD requires restoration of the barrier function without altering normal physiologic function such as belching and is simple, reproducible, less invasive and reversible if necessary. Each of the reviewed modalities has altered the LES in a novel way to achieve this goal. The LINX system acts as a loose ligature around the LES preventing shortening and thus transient LES opening. TIF endoscopically creates a partial fundoplication that theoretically should enhance the angle of His and prevent LES opening. EndoStim increases LESP through electrical stimulation while allowing normal LES relaxation, and Stretta alters the neuromuscular function of the LES and gastric cardia via RFA.

The result, regardless of the mechanism, is an improvement in the patient's GERD symptoms and improved quality of life. What is surprising is that objective control of GERD based on $\mathrm{pH}$ data did not support the subjective improvement except in patients who received a LINX device who had normal mean post-procedure DeMeester scores of 13.5 [9] or who underwent EndoStim with post-procedure DeMeester scores of 11.7 [23•]. It is unclear why there is a discordance between the subjective and objective findings. It could represent a placebo effect or an alteration in the way the patient senses reflux.

However, when these new treatments are evaluated by the defined measures of successful GERD treatment-symptoms, objective measures of acid control and the need for additional therapy [6•]_TIF and Stretta fall short when evaluated by control of acid reflux as measured by $\mathrm{pH}$ assessment. Moreover, both TIF and Stretta patients appear to require additional procedures or treatments frequently. EndoStim, while it meets the criteria, is very limited in the number of patients that have completed clinical trials. LINX device implantation appears to be the most promising new approach to GERD with symptomatic improvement, objective control of $\mathrm{pH}$ measures and very few additional procedures or treatments required for reflux control.

Lastly, it should be recognized that none of the four devices has been compared in either a cohort or randomized fashion to PPIs or fundoplication. The reported experience with any device has been limited, and the follow-up ranges from 6 months to 6 years. Obviously, greater experience is required particularly with the LINX and EndoStim devices to validate their early results with subjective and objective measures of durability over a longer follow-up period.

\section{Conclusions}

Each of the current GERD treatment options (PPIs, LNF) has limitations in terms of objective efficacy measures and may also have potentially unpalatable side effects for the patient. Four new devices, LINX, TIF, EndoStim and Stretta, have attempted to improve upon these limitations. While each is promising, only the LINX device addresses the patient's symptoms, achieves objective control of acid and has reported limited need for additional therapies. Further comparative research and longer follow-up are necessary to determine the role of these therapies in the algorithm of GERD management.

\section{Compliance with Ethics Guidelines}

Conflict of interest Jennifer L. Wilson declares that she has no conflict of interest. Brian E. Louie has had travel/accommodations expenses covered/reimbursed by Torax Medical.

Human and Animal Rights and Informed Consent This article does not contain any studies with human or animal subjects performed by any of the authors. 


\section{References}

Recently published papers of particular interest have been highlighted as:

- Of importance

1. El-Serag HB, Sweet S, Winchester CC, Dent J. Update on the epidemiology of gastro-oesophageal reflux disease: a systematic review. Gut. 2013. doi:10.1136/gutjnl-2012-304269.

2. Kahrilas PJ, Miner P, Johanson J, Mao L, Jokubaitis L, Sloan S. Efficacy of rabeprazole in the treatment of symptomatic gastroesophageal reflux disease. Dig Dis Sci. 2005;50(11):2009-18.

3. Wilhelm SM, Rjater RG, Kale-Pradhan PB. Perils and pitfalls of long-term effects of proton pump inhibitors. Expert Rev Clin Pharmacol. 2013;6(4):443-51.

4. Lundell L, Miettinen P, Myrvold HE, Hatlebakk JG, Wallin L, Malm A, et al. Seven-year follow-up of a randomized clinical trial comparing proton-pump inhibition with surgical therapy for reflux oesophagitis. Br J Surg. 2007;94(2):198-203.

5. - Galmiche J-P, Hatlebakk J, Attwood S, Ell C, Fiocca R, Eklund S, et al. Laparoscopic antireflux surgery vs esomeprazole treatment for chronic GERD: the LOTUS randomized clinical trial. JAMA J Am Med Assoc. 2011;305(19):1969-77. The LOTUS trial was a landmark RCT comparing surgical fundoplication vs. PPIs and found durable results for both at 5 years with relatively high morbidity for LNF $(11 \%$ dysphagia versus $5 \%$ for PPIs $p<0.001)$.

6. - Oelschlager BK, Ma KC, Soares RV, Montenovo MI, Munoz Oca JE, Pellegrini CA. A broad assessment of clinical outcomes after laparoscopic antireflux surgery. Ann Surg. 2012;256(1):87-94. How we measure GERD treatment success is explored in this study which stresses the importance of durability, minimal morbidity and subjective/objective measurs of success. This study is important because many studies do not report all of these measures which can make comparisons between treatment modalities difficult.

7. Lundell L, Miettinen P, Myrvold HE, Hatlebakk JG, Wallin L, Engström C, et al. Comparison of outcomes twelve years after antireflux surgery or omeprazole maintenance therapy for reflux esophagitis. Clin Gastroenterol Hepatol. 2009;7(12):1292-8 quiz 1260.

8. Samelson SL, Weiser HF, Bombeck CT, Siewert JR, Ludtke FE, Hoelscher AH, et al. A new concept in the surgical treatment of gastroesophageal reflux. Ann Surg. 1983;197(3):254-9.

9. - Ganz RA, Peters JH, Horgan S, Bemelman WA, Dunst CM, Edmundowicz SA, et al. Esophageal sphincter device for gastroesophageal reflux disease. N Engl J Med. 2013;368(8):719-27. Prospective study of 100 patients who underwent LINX for GERD with 5-year results.

10. Bonavina L, Saino G, Bona D, Sironi A, Lazzari V. One hundred consecutive patients treated with magnetic sphincter augmentation for gastroesophageal reflux disease: 6 years of clinical experience from a single center. J Am Coll Surg. 2013;217(4):577-85.

11. Cadière GB, Rajan A, Rqibate M, Germay O, Dapri G, Himpens $\mathrm{J}$, et al. Endoluminal fundoplication (ELF)-evolution of EsophyX, a new surgical device for transoral surgery. Minim Invasive Ther Allied Technol. 2006;15(6):348-55.

12. Cadière GB, Rajan A, Germay O, Himpens J. Endoluminal fundoplication by a transoral device for the treatment of GERD: a feasibility study. Surg Endosc. 2008;22(2):333-42.

13. Cadière G-B, Buset M, Muls V, Rajan A, Rösch T, Eckardt AJ, et al. Antireflux transoral incisionless fundoplication using EsophyX: 12-month results of a prospective multicenter study. World J Surg. 2008;32(8):1676-88.

14. - Bell RCW, Mavrelis PG, Barnes WE, Dargis D, Carter BJ, Hoddinott $\mathrm{KM}$, et al. A prospective multicenter registry of patients with chronic gastroesophageal reflux disease receiving transoral incisionless fundoplication. J Am Coll Surg. 2012;215(6):794-809. Prospective multicenter registry, one of the largest TIF studies published to date.

15. Bell RCW, Cadière G-B. Transoral rotational esophagogastric fundoplication: technical, anatomical, and safety considerations. Surg Endosc. 2011;25(7):2387-99.

16. Bell RCW, Freeman KD. Clinical and $\mathrm{pH}$-metric outcomes of transoral esophagogastric fundoplication for the treatment of gastroesophageal reflux disease. Surg Endosc. 2011;25(6):1975-84.

17. Witteman BPL, Strijkers R, de Vries E, Toemen L, Conchillo JM, Hameeteman W, et al. Transoral incisionless fundoplication for treatment of gastroesophageal reflux disease in clinical practice. Surg Endosc. 2012;26(11):3307-15.

18. Rinsma NF, Smeets FG, Bruls DW, Kessing BF, Bouvy ND, Masclee AAM, et al. Effect of transoral incisionless fundoplication on reflux mechanisms. Surg Endosc. 2014;28(3):941-9.

19. Perry KA, Linn JG, Eakin JL, Onders RP, Velanovich V, Melvin WS. Transoral incisionless fundoplication does not significantly increase morbidity of subsequent laparoscopic nissen fundoplication. J Laparoendosc Adv Surg Tech A. 2013;23(5):456-8.

20. Furnée EJB, Broeders JAJL, Draaisma WA, Schwartz MP, Hazebroek EJ, Smout AJPM, et al. Laparoscopic Nissen fundoplication after failed EsophyX fundoplication. Br J Surg. 2010;97(7):1051-5.

21. Rodríguez L, Rodríguez P, Neto MG, Ayala JC, Saba J, Berel D, et al. Short-term electrical stimulation of the lower esophageal sphincter increases sphincter pressure in patients with gastroesophageal reflux disease. Neurogastroenterol Motil. 2012;24(5):446-50 e213.

22. Rodríguez L, Rodriguez P, Gómez B, Ayala JC, Saba J, PerezCastilla A, et al. Electrical stimulation therapy of the lower esophageal sphincter is successful in treating GERD: final results of open-label prospective trial. Surg Endosc. 2013;27(4):1083-92.

23. - Rodríguez L, Rodriguez P, Gómez B, Ayala JC, Oksenberg D, Perez-Castilla A, et al. Long-term results of electrical stimulation of the lower esophageal sphincter for the treatment of gastroesophageal reflux disease. Endoscopy. 2013;45(8):595-604. Twelve-month follow-up data of 24 patients treated with Endostim.

24. Tam WCE, Schoeman MN, Zhang Q, Dent J, Rigda R, Utley D, et al. Delivery of radiofrequency energy to the lower oesophageal sphincter and gastric cardia inhibits transient lower oesophageal sphincter relaxations and gastro-oesophageal reflux in patients with reflux disease. Gut. 2003;52(4):479-85.

25. Arts J, Bisschops R, Blondeau K, Farré R, Vos R, Holvoet L, et al. A double-blind sham-controlled study of the effect of radiofrequency energy on symptoms and distensibility of the gastro-esophageal junction in GERD. Am J Gastroenterol. 2012;107(2):222-30.

26. Dughera L, Navino M, Cassolino P, De Cento M, Cacciotella L, Cisarò $\mathrm{F}$, et al. Long-term results of radiofrequency energy delivery for the treatment of GERD: results of a prospective 48-month study. Diagn Ther Endosc. 2011;2011:507157.

27. - Perry KA, Banerjee A, Melvin WS. Radiofrequency energy delivery to the lower esophageal sphincter reduces esophageal acid exposure and improves GERD symptoms: a systematic review and meta-analysis. Surg Laparosc Endosc Percutan Tech. 2012;22(4):283-8. Large meta-analysis compiling Stretta data from 20 studies (1441 patients).

28. Triadafilopoulos G, DiBaise JK, Nostrant TT, Stollman NH, Anderson PK, Wolfe MM, et al. The Stretta procedure for the treatment of GERD: 6 and 12 month follow-up of the U.S. open label trial. Gastrointest Endosc. 2002;55(2):149-56.

29. Noar MD, Lotfi-Emran S. Sustained improvement in symptoms of GERD and antisecretory drug use: 4-year follow-up of the Stretta procedure. Gastrointest Endosc. 2007;65(3):367-72.

30. Bonavina L, Saino GI, Bona D, Lipham J, Ganz RA, Dunn D, et al. Magnetic augmentation of the lower esophageal sphincter: results of a feasibility clinical trial. J Gastrointest Surg. 2008;12(12):2133-40. 